\title{
Exploring the Potential of Personalized Dietary Advice for Health Improvement in Motivated Individuals With Premetabolic Syndrome: Pretest-Posttest Study
}

Sandra van der Haar ${ }^{1 *}$, MSc; Femke P M Hoevenaars ${ }^{2 *}$, MSc, PhD; Willem J van den Brink ${ }^{2}$, MSc, PhD; Tim van den Broek $^{2}$, MSc; Mariëlle Timmer ${ }^{1}$, MSc; André Boorsma ${ }^{2}, \mathrm{MSc}, \mathrm{PhD}$; Esmée L Doets ${ }^{1}$, MSc, PhD

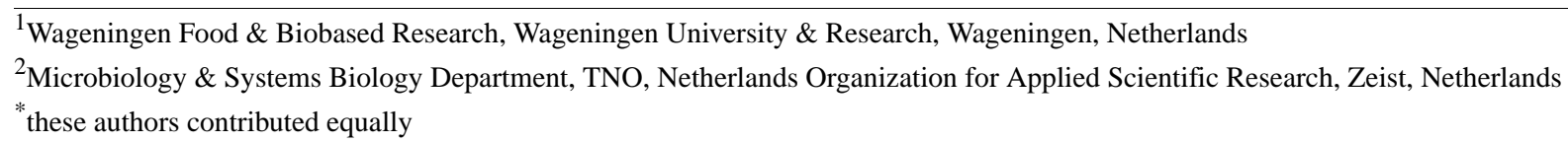

\section{Corresponding Author:}

Sandra van der Haar, MSc

Wageningen Food \& Biobased Research

Wageningen University \& Research

Bornse Weilanden 9

Wageningen, $6708 \mathrm{WG}$

Netherlands

Phone: 310317480171

Email: sandra.vanderhaar@wur.nl

\section{Abstract}

Background: Dietary quality plays an essential role in the prevention and management of metabolic syndrome (MetS).

Objective: The aim of this pilot study is to organize personalized dietary advice in a real-life setting and to explore the effects on dietary intake, metabolic health, and perceived health.

Methods: We followed a one-group pretest-posttest design and included 37 individuals at risk of MetS, who indicated motivation to change dietary behavior. For a period of 16 weeks, participants received personalized advice $(t=0$ and $t=8)$ and feedback $(t=0$, $\mathrm{t}=4, \mathrm{t}=8, \mathrm{t}=12$ and $\mathrm{t}=16$ ) on dietary quality and metabolic health (ie, waist circumference, BMI, blood pressure, lipid profile, fasting glucose levels, and C-peptide). Personalized advice was generated in a two-stage process. In stage 1, an automated algorithm generated advice per food group, integrating data on individual dietary quality (Dutch Healthy Diet Index; total score 8-80) and metabolic health parameters. Stage 2 included a telephone consultation with a trained dietitian to define a personal dietary behavior change strategy and to discuss individual preferences. Dietary quality and metabolic health markers were assessed at $\mathrm{t}=0, \mathrm{t}=8$, and $\mathrm{t}=16$. Self-perceived health was evaluated on 7-point Likert scales at $\mathrm{t}=0$ and $\mathrm{t}=16$.

Results: At the end of the study period, dietary quality was significantly improved compared with the baseline (Dutch Healthy Diet Index $+4.3 ; P<.001$ ). In addition, lipid profile (triglycerides, $P=.02$; total cholesterol, $P=.01$; high-density lipoprotein, $P<.001$; and low-density lipoprotein, $P<.001)$, BMI $(P<.001)$, waist circumference $(P=.01)$, and C-peptide $(P=.01)$ were all significantly improved, whereas plasma glucose increased by $0.23 \mathrm{nmol} / \mathrm{L}(P=.04)$. In line with these results, self-perceived health scores were higher at $\mathrm{t}=16$ weeks than at baseline $(+0.67 ; P=.005)$.

Conclusions: This exploratory study showed that personalized dietary advice resulted in positive effects on dietary behavior, metabolic health, and self-perceived health in motivated pre-MetS adults. The study was performed in a do-it-yourself setting, highlighting the potential of at-home health improvement through dietary changes.

Trial Registration: ClinicalTrials.gov NCT04595669; https://clinicaltrials.gov/ct2/show/NCT04595669

(JMIR Form Res 2021;5(6):e25043) doi: 10.2196/25043

\section{KEYWORDS}

personalized nutrition; metabolic syndrome; dietary behavior; diet; metabolic; metabolic health; dietary advice; dietary feedback; digital health 


\section{Introduction}

\section{Background}

Metabolic syndrome (MetS) is associated with a two-fold increased risk of cardiovascular diseases and a five-fold increased risk of type 2 diabetes [1,2]. Approximately $25 \%$ of adults globally are affected by MetS, and its prevalence increases with age $[3,4]$. MetS is defined by the coexistence of three or more of the following risk factors: abdominal obesity, high fasting blood glucose, reduced high-density lipoprotein (HDL) cholesterol, elevated fasting plasma triglycerides, and elevated blood pressure (BP) [5].

Unhealthy dietary habits are a major risk factor for developing MetS and are probably even more relevant than sedentary lifestyles [6]. Research has demonstrated dietary strategies that can be used to prevent or resolve MetS and associated metabolic abnormalities [6-9]. Adherence to a healthy diet rich in fruits, vegetables, whole grains, and oily fish, while limiting total fat, saturated fat, dietary cholesterol, added sugars, sodium, and excessive alcohol intake, has been shown to be effective in improving metabolic abnormalities associated with MetS $[7,8,10]$. Associations between dietary changes and individual risk factors for MetS have also been shown [11-21].

Personalized nutrition, that is, evidence-based dietary advice tailored toward an individual based on individual-specific information, is most likely an effective strategy to support dietary behavior change, resulting in measurable health benefits [22]. Previous studies have shown that personalized advice is more effective than giving a one-size-fits-all advice for improving dietary patterns, increasing physical activity and smoking cessation [23-30].

We distinguished two potential reasons for this effectiveness. First, each person receives advice that addresses the individual nutritional needs based on the person's biology, thereby maximizing the individual health effect. In a study on healthy volunteers receiving placebo or anti-inflammatory dietary mix supplements, the inflammatory, oxidative, and metabolic responses were highly variable among individuals, suggesting different nutritional needs based on the person's biology [31]. Indeed, the concept of personalized nutrition from a biological perspective began to emerge as extensively reviewed by van Ommen et al in 2017 [32].

A second reason for personalized nutrition being effective is increased adherence to the advice when it is made personal. Each person receives only the information based on their characteristics, rather than generic information based on the characteristics of the population. Therefore, people are more likely to pay attention and feel more involved, especially when the information is tailored to the personal level of motivation [23].
Celis-Moralis et al reviewed the evidence on personalized interventions and concluded that there is a strong need for further development, testing, and implementation of digitally delivered, evidence-based, personalized interventions that incorporate effective behavior change techniques (eg, personal goal setting and feedback on performance) and are delivered digitally [33,34]. In a web-based multicenter study, Forster et al [35] compared an automated feedback system with manual feedback and found good agreement between the manual and automated feedback systems, showing promise for the use of automated systems for personalizing dietary advice. With regard to scalability and expected contribution to sustained behavior change, new evidence on the effectiveness and acceptance of these digitally delivered interventions is highly relevant.

\section{Objectives}

The primary aim of this pilot study is to organize personalized dietary advice in a real-life setting. We build upon the research described by Doets et al [36] by exploring the combined effects of dietary intake, metabolic health, and perceived health. As we aim to conduct real-life implementation, we are targeting individuals at risk of MetS, who are intrinsically motivated to change their dietary behavior to improve their health, as they are likely to be easy adopters of personalized advice.

\section{Methods}

\section{Ethics Statement}

All participants provided informed consent for inclusion before they participated in the study. The study was conducted in accordance with the Declaration of Helsinki, and the protocol was approved by the Ethics Committee of Tilburg University (file number NL61382.028.17).

\section{Recruitment and Screening}

An overview of the recruitment procedure is shown in Figure 1. First, all members of the consumer database of Wageningen University \& Research received an invitation letter for the study. Those interested in study participation completed a web-based screening questionnaire to verify the first set of inclusion and exclusion criteria: age $\geq 40$ years, excessive waist circumference (self-reported $\geq 88 \mathrm{~cm}$ for women and $\geq 102 \mathrm{~cm}$ for men), positive intention toward changing dietary behavior, and willingness to use digital web-based applications during the study. To assess intention toward behavior change, we used an adapted version of 3 questions (7-point Likert scale) reported by Poinhos et al [37]. Participants with a mean score of $\geq 5$ were considered to be motivated to change their dietary behavior. Exclusion criteria were as follows: taking medication known for its effects on blood glucose, cholesterol, or insulin; being diagnosed with diabetes or familial hypercholesterolemia; following a specific diet or having an alcohol consumption of $>28$ units (drinks) per week for men and > 21 units per week for women. 
Figure 1. Flowchart of recruitment and screening procedure. HDL: high-density lipoprotein.

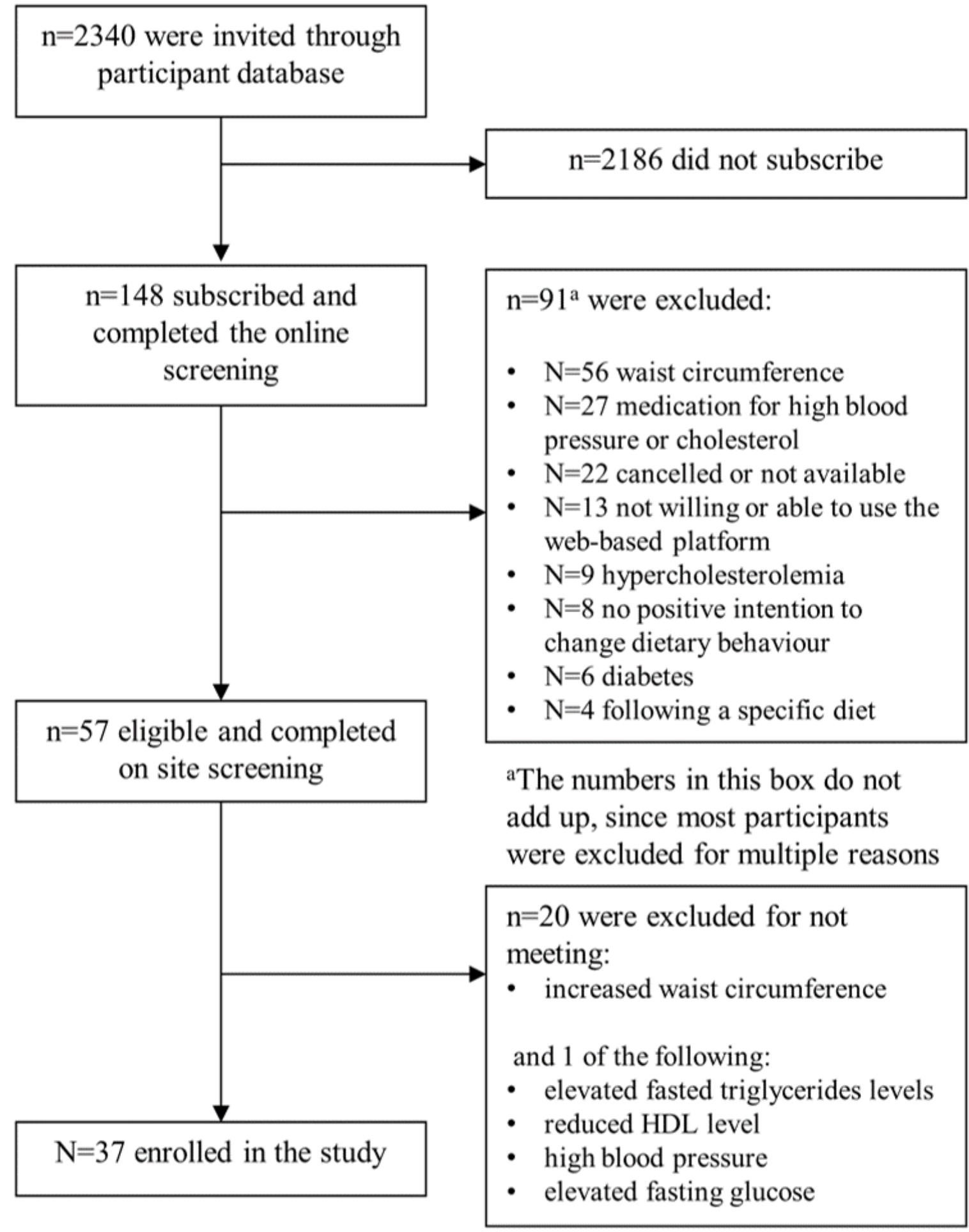

To improve health and behavioral changes through personalized advice, we included individuals at risk of MetS (second set of inclusion criteria). Therefore, individuals eligible for study participation were invited for additional screening to verify whether they were at risk of MetS, defined as an excessive waist circumference ( $\geq 88 \mathrm{~cm}$ for women and $\geq 102 \mathrm{~cm}$ for men) combined with elevated fasted triglycerides levels $(\geq 1.7$ $\mathrm{mmol} / \mathrm{L})$, reduced HDL level $(<1.03 \mathrm{mmol} / \mathrm{L}$ for men and $<1.29$ $\mathrm{mmol} / \mathrm{L}$ for women), high $\mathrm{BP}$ (systolic: $\geq 130 \mathrm{~mm} \mathrm{Hg}$ or diastolic: $\geq 85 \mathrm{~mm} \mathrm{Hg}$ ), or elevated fasting glucose $(>5.6$ $\mathrm{mmol} / \mathrm{L})$.

On the basis of the study by Doets et al [36], we performed a power calculation to estimate an adequate sample size to identify potential health effects. The effect size was based on the mean change in waist circumference $(\delta=1.85 \mathrm{~cm}$, SD 2.67; significance level of $5 \%$ ). The calculations revealed that a sample size of 16 would be sufficient to identify potential health effects based only on waist circumference. However, based on 
the sample sizes of previous pilot studies $[36,38]$ and taking into account various combinations of MetS risk factors and potential dropout, we increased the number of participants to 40 .

\section{Study Design}

The study followed a one-group pretest-posttest design with a duration of 16 weeks (Table 1). Reviews of behavioral intervention studies have shown that a period of 16 weeks is minimal to allow the first stages of behavior change $[39,40]$.
Our study targeted individuals who were motivated to change their dietary behavior; therefore, a period of 16 weeks was considered sufficient. As the aim of the study was to explore the potential effects of personalized nutrition in real life, no control group was included. The intervention consisted of personalized dietary advice in combination with feedback on dietary behavior and health status (ie, waist circumference, BP, cholesterol, glucose, BMI, C-peptide, and triglycerides) at set time points throughout the study.

Table 1. Overview of study design: measurements, interventions, and planning.

\begin{tabular}{|c|c|}
\hline Measurements and characteristics of the intervention & Timepoints (weeks), $\mathrm{t}$ \\
\hline \multicolumn{2}{|l|}{ Diet } \\
\hline Diet quality (Dutch Healthy Diet Index) per food category and total score & $0,8,16$ \\
\hline Carotenoids in blood (biomarker fruit and vegetable intake) & $0,8,16$ \\
\hline Food purchase data at retailer (via customer card) & 4,12 \\
\hline \multicolumn{2}{|l|}{ Subjective health } \\
\hline Self-perceived health questionnaire & 0,16 \\
\hline \multicolumn{2}{|l|}{ Consumer experiences } \\
\hline Evaluation questionnaire & 16 \\
\hline \multicolumn{2}{|l|}{ Metabolic health } \\
\hline Waist circumference & $0,8,16$ \\
\hline BMI & $0,8,16$ \\
\hline Blood pressure & $0,8,16$ \\
\hline Lipid profile (total cholesterol, $\mathrm{HDL}^{\mathrm{a}}, \mathrm{LDL}^{\mathrm{b}}$, and triglycerides) & $0,8,16$ \\
\hline Fasting glucose & $0,8,16$ \\
\hline C-peptide & $0,8,16$ \\
\hline \multicolumn{2}{|l|}{ Personalized advice } \\
\hline Stage 1: automated advice based on individual diet quality and metabolic health status & 0,8 \\
\hline Stage 2: telephone consultation with dietitian to define behavioral change strategy and discuss personal preferences & 0,8 \\
\hline \multicolumn{2}{|l|}{ Feedback } \\
\hline Diet quality discussed in telephone consultations with dietitian & 0,8 \\
\hline Alternatives for product purchases in email messages from dietitian & 4,12 \\
\hline Metabolic health via web-based platform & $0,8,16$ \\
\hline Integrated personal health score via web-based platform & 0,16 \\
\hline
\end{tabular}

${ }^{a}$ HDL: high-density lipoprotein.

${ }^{b}$ LDL: low-density lipoprotein.

\section{Study Procedures}

During the 3 test days ( $\mathrm{t}=0, \mathrm{t}=8$, and $\mathrm{t}=16$ weeks), participants arrived in the morning in a fasted state to Wageningen University and Research, the Netherlands. Metabolic health parameters were assessed by trained research nurses using do-it-yourself devices, following standard operating procedures. Total cholesterol, HDL, low-density lipoprotein (LDL), and triglycerides were measured in finger-prick blood using the Mission Cholesterol 3-in-1 device (Acon Labs Inc). Glucose levels were assessed using a MediTouch 2 blood glucose meter
(Medisana). BP was measured using a Medisana upper arm BP monitor. Both glucose and BP were measured twice for each participant, and the average result was used as input for feedback and personalized advice.

\section{Dietary Quality}

Dietary quality was assessed by using a web-based version of the Dutch Healthy Diet Index (DHDI; Eetscore, Division of Human Nutrition, Wageningen University) [41]. The DHDI evaluates adherence to the Dutch dietary guidelines per food category (score 1-10) and total score (score 8-80). In this study, 
we focused on food categories that have been shown to be effective for improving metabolic abnormalities due to reducing calorie intake or through direct effects on metabolic parameters. These food categories are fruit and vegetables [16,17,19], wholegrain products $[13,14,16]$, dairy products $[17,18,20]$, fish [10,16,21], saturated fat (butter, meat, and snacks) [12], and sugar-containing beverages [17]. The DHDI results were used as input for the dietary advice tool.

\section{Metabolic Health Parameters}

Waist circumference was determined directly over the skin at the midpoint between the lower part of the last rib and the top of the hip. Body weight was recorded on a calibrated weighing scale to the nearest $0.1 \mathrm{~kg}$. Finger-prick blood was blotted on dried blood spot (DBS) cards (Protein Saver TM 903R Cards, Whatman). To suppress the degradation of carotenoids in the DBS samples, the first two circles in the DBS cards were impregnated with a proprietary stabilizing solution supplied by Vitas AS. After air drying for several hours, the cards were stored in airtight resealable aluminum bags (Whatman) with a desiccant pouch (Reàl Marine A/S Stavanger) to remove any moisture from the DBS cards. C-peptide and carotenoids were assessed via high-performance liquid chromatography with UV detection and liquid chromatography-mass spectrometry (Vitas AS) [42]. In brief, from each DBS, 3·2-mm disks were punched out and mixed with distilled water. Next, proteins were precipitated and carotenoids were extracted with isopropanol containing an internal standard ( $\beta$-Apo-8 carotenal, Sigma-Aldrich). An aliquot of the isopropanol phase was analyzed using a 1100-series HPLC-UV system with a 1260 diode array detector (453 nm; Agilent Technologies). Separation was performed on a 3-mm YMC C30 column (150 mm×4.6 $\mathrm{mm}$ internal diameter, YMC).

\section{Personalized Dietary Advice}

At $\mathrm{t}=0$ and $\mathrm{t}=8$ weeks, the participants received personalized dietary advice. Personalized advice was generated in a two-stage process. During stage 1, the content of the advice was defined based on individual dietary habits (ie, DHDI and carotenoid levels as a biomarker of fruit and vegetable intake) and parameters of metabolic health. The results of these measurements were added to an automated personalized dietary advice system. First, the algorithm evaluated per food category (dairy, fats and oils, fish, fruit, nuts, sugar-containing beverages, vegetables, and wholegrain products) whether intake and nutrient status were sufficient based on predefined cut-off levels. If intake or nutrient status was insufficient, the food category was included in the advice. Second, the system evaluated the presence of metabolic abnormalities. If metabolic abnormalities were present, relevant food categories were included in the advice to emphasize the importance of adequate intake for a specific food category.
Stage 2 included a telephone consultation of 45-60 minutes, during which a trained dietitian discussed the system-generated advice with the participant following a standard protocol. During the consultation, a personal dietary behavior change strategy was defined by adapting the advice from stage 1 to individual preferences (eg, number of food groups to work on, selection of alternative products, and adjustment of portion sizes). In Table S1 of Multimedia Appendix 1, the steps followed by the dietitian are displayed. A summary of the dietary behavior change strategy was available to the participants through a web-based personal study portal. The provided dietary advice was in line with the national dietary recommendations provided by the Health Council of the Netherlands and the Netherlands Nutrition Centre [43,44].

\section{Feedback}

Feedback on behavioral parameters was provided to participants by a dietitian as part of the individual telephone consultations at $\mathrm{t}=0$ and $\mathrm{t}=8$ weeks and via email at $\mathrm{t}=4$ and $\mathrm{t}=12$ weeks. The feedback by telephone addressed adherence to Dutch dietary guidelines based on the DHDI. The feedback by email addressed healthy alternatives for recent product choices and was based on purchase data registered on a supermarket customer card that participants were asked to share with the research team. Feedback on metabolic health parameters (ie, waist circumference, BMI, BP, glucose, cholesterol, C-peptide, and triglycerides) was directly communicated to the subjects via a web-based personal study portal at $\mathrm{t}=0, \mathrm{t}=8$, and $\mathrm{t}=16$ weeks.

Furthermore, at $\mathrm{t}=0$ and $\mathrm{t}=16$ weeks, each participant received an integrated personal health score based on their metabolic health parameters.

\section{Personal Health Score}

The personal health score was produced using a so-called health space model that was created on basis of the principle of van den Broek et al [45]. This type of model can produce an individual unitless score based on personal data that correspond to the individuals' health status after being trained on the data of two reference groups. The model in this study was trained on two reference groups from an independent data set (National Health and Nutrition Examination Survey 2003-2004 [2003]; [46]), a group of healthy subjects with no diagnostic characteristic for MetS versus subjects diagnosed with MetS (Table 2). The MetS group was selected based on the MetS definition of the International Diabetes Federation [47]. In turn, 135 subjects in the healthy group were selected from all available subjects by constraining BMI between 18 and 25 $\mathrm{kg} / \mathrm{m}^{2}$. Of these 135 subjects, the top 10 were selected based on their aggregated rank. 
Table 2. Demographics and metabolic health parameters of study participants and the health space reference groups (N=85).

\begin{tabular}{|c|c|c|c|}
\hline Variable & Study participants $(\mathrm{n}=34)$ & Healthy reference $^{\mathrm{a}}(\mathrm{n}=10)$ & Met $^{\mathrm{b}}$ reference $^{\mathrm{a}}(\mathrm{n}=41)$ \\
\hline \multicolumn{4}{|l|}{ Sex, n (\%) } \\
\hline Male & $9(26)$ & $5(50)$ & $19(46)$ \\
\hline Female & $25(74)$ & $5(50)$ & $22(54)$ \\
\hline Age (years), mean (SD) & $61(8.2)$ & $57.6(16.2)$ & $54(21.0)$ \\
\hline BMI $\left(\mathrm{kg} / \mathrm{m}^{2}\right)$, mean (SD) & $29.9(4.18)$ & $21.3(1.88)$ & $31.1(5.68)$ \\
\hline Waist circumference $(\mathrm{cm})$, mean $(\mathrm{SD})$ & $102(11.4)$ & $83.2(4.68)$ & $105(10.8)$ \\
\hline Total cholesterol (mmol/L), mean (SD) & $6.23(0.78)$ & $5.32(1.10)$ & $4.77(1.02)$ \\
\hline $\mathrm{HDL}^{\mathrm{c}}$ cholesterol $(\mathrm{mmol} / \mathrm{L})$, mean $(\mathrm{SD})$ & $1.14(0.27)$ & $1.49(0.37)$ & $1.01(0.13)$ \\
\hline $\mathrm{LDL}^{\mathrm{d}}$ cholesterol $(\mathrm{mmol} / \mathrm{L})$, mean $(\mathrm{SD})$ & $4.34(0.74)$ & $3.12(1.02)$ & $2.73(0.99)$ \\
\hline Triglycerides (mmol/L), mean (SD) & $1.67(0.85)$ & $1.57(0.52)$ & $2.25(0.95)$ \\
\hline Glucose $(\mathrm{mmol} / \mathrm{L})$, mean $(\mathrm{SD})$ & $5.61(0.65)$ & $5.33(0.70)$ & $7.07(3.08)$ \\
\hline C-peptide (nmol/L), mean (SD) & $0.52(0.33)$ & $0.75(0.40)$ & $1.46(0.90)$ \\
\hline Systolic blood pressure $(\mathrm{mm} \mathrm{Hg})$, mean (SD) & $135(18.0)$ & $138(18.5)$ & $128(21.5)$ \\
\hline Diastolic blood pressure (mm Hg), mean (SD) & $78.6(9.54)$ & $77.7(14.0)$ & $67.4(18.6)$ \\
\hline
\end{tabular}

${ }^{\mathrm{a}}$ Data for the reference groups were obtained from the National Health and Nutrition Examination Survey 2003-2004 (CDC 2003) [46].

${ }^{\mathrm{b}}$ MetS: metabolic syndrome.

${ }^{\mathrm{c}} \mathrm{HDL}$ : high-density lipoprotein.

${ }^{\mathrm{d}}$ LDL: low-density lipoprotein.

This aggregated rank is based on the features included in the trained model, where the highest rank corresponds to the healthiest values of these features. The aggregated rank of this collection of features was calculated using the robust rank aggregation algorithm proposed by Kolde et al [48]. The data used in the training of this model were taken from the National Health and Nutrition Examination Survey 2003-2004 data set (CDC 2003) [46].

A multivariate mixed-effects regression model was subsequently fitted to the data from the two selected reference groups with good classification performance with an accuracy of $99 \%$ and a Cohen $\kappa$ coefficient of 0.94 . The model includes triglycerides, LDL cholesterol, HDL cholesterol, glucose, and C-peptide as fixed effects and sex as a random effect. The random effect was included to allow for sex differences in the final model coefficients. Table S2 in Multimedia Appendix 1 shows the standardized contributions of each feature in the final model. Finally, individual health scores were calculated by feeding participants' metabolic health data into the regression model.

\section{Self-Perceived Health and Consumer Experiences}

At baseline and at the end of the study, participants reported self-perceived health, self-perceived healthiness of the diet, and satisfaction with the diet using a 7-point Likert scale ranging from $1=$ very unhealthy to $7=$ very healthy and $1=$ very unsatisfied to $7=$ very satisfied.

At the end of the study, participants filled out an evaluation questionnaire on personal experiences regarding advice, feedback, and the digital platform (statements on 7-point Likert

scales, ranging from $1=$ completely disagree to $7=$ completely agree).

\section{Statistical Analyses}

Data on DHDI scores and metabolic health were analyzed using linear mixed models with time ( $\mathrm{t}=0 \mathrm{vs} \mathrm{t}=8 \mathrm{vs} \mathrm{t}=16$ weeks) as a fixed effect and subject as a random effect. Self-perceived health data were evaluated using ordinal mixed regression models with the same model structure. Post hoc analyses were performed on these models to identify significant differences between the individual time points. In the linear mixed model, observations with an absolute residual $>3$ times the root mean square error of the model were treated as statistical outliers.

In addition, Pearson correlation coefficients were calculated between the $\Delta$ of the single dietary behavior variables and the single metabolic health variables and between the $\Delta$ of dietary behavior and metabolic health variables. Only significant correlations that could be visually confirmed in the scatterplots were regarded as reliable (Figure S1 in Multimedia Appendix 1).

For the analyses of the individual food categories, only participants that actually incorporated the specific food category in their dietary behavior change strategy were included. $P$ values reported from the mixed model post hoc tests were adjusted for multiple comparisons following the Benjamini-Hochberg procedure [49].

Statistical significance was set at $P<.05$ for all analyses. Statistical analyses were performed using $\mathrm{R}$ version 3.4.3 (R Core Team). 


\section{Results}

\section{Baseline Characteristics}

A total of 37 individuals were enrolled in this study. During the study period, 3 subjects dropped out: 1 participant no longer met the inclusion criteria, and the other 2 experienced too many difficulties in using the web-based platform. The baseline characteristics of the 34 participants who completed the intervention as well as the reference populations used for modeling the health score are summarized in Table 2. Next to excessive waist circumference, most participants presented multiple risk factors for MetS. High BP, high glucose, high triglycerides, and low HDL were present in 21, 16, 14, and 22 subjects, respectively.

\section{Effect of Personalized Advice on Dietary Quality}

Most subjects $(33 / 34,97 \%)$ were provided with advice on multiple food categories in their individual dietary behavior change strategies. One participant chose to focus on only one food category. Advice was provided most frequently on vegetables $(31 / 34,91 \%)$, followed by oils and fat $(21 / 34,62 \%)$, nuts $(20 / 34,59 \%)$, wholegrain products $(19 / 34,56 \%)$, dairy $(14 / 34,41 \%)$, fish $(12 / 34,35 \%)$, fruit $(9 / 34,27 \%)$, and sugar-containing beverages $(3 / 34,9 \%)$. The mean DHDI scores over time per food category are shown in Table 3. An improvement over time was observed for wholegrain products $(+1.6 ; P=.009 ; 19 / 34,56 \%)$, nuts $(+2.2 ; P=.009 ; 20 / 34,59 \%)$, and total DHDI $(+4.3 ; P<.001 ; 34 / 34,100 \%)$. The change in total DHDI was significantly correlated in decreasing order with the change in oils and fats score $(\rho=0.62 ; P<.001)$, nuts score $(\rho=0.62 ; P<.001)$, dairy score $(\rho=0.55 ; P<.001)$, fish score $(\rho=0.39 ; P=.03)$, and fruit score $(\rho=0.39 ; P=.02)$.

Table 3. Dutch Healthy Diet Index per food category (score 1-10) and total score (score 8-80) and total carotenoids ( $\mu$ mol/L) at baseline, 8 weeks, and 16 weeks.

\begin{tabular}{|c|c|c|c|c|}
\hline \multirow[t]{2}{*}{ Food category $^{\mathrm{a}}$} & \multicolumn{3}{|c|}{ DHDI $^{\mathrm{b}}$ score, mean (SD) } & \multirow[t]{2}{*}{$P$ value } \\
\hline & $\mathrm{t}=0$ weeks & $\mathrm{t}=8$ weeks & $\mathrm{t}=16$ weeks & \\
\hline Vegetable intake $(\mathrm{n}=31)$ & $6.6(2.9)$ & $7.5(3.0)$ & $7.1(3.3)$ & .53 \\
\hline Fruit intake $(\mathrm{n}=9)$ & $5.8(3.3)$ & $8.2(2.0)$ & $8.4(2.0)$ & .70 \\
\hline Intake of oils and fats $(n=21)$ & $3.7(3.9)$ & $3.6(4.1)$ & $3.5(3.8)$ & .85 \\
\hline Fish intake $(\mathrm{n}=12)$ & $6.6(3.2)$ & $7.5(2.6)$ & $8.6(1.9)$ & .18 \\
\hline Intake of wholegrain products $(n=19)$ & $6.3(2.5)^{\mathrm{c}}$ & $7.7(2.8)^{\mathrm{c}}$ & $7.9(2.8)^{\mathrm{c}}$ & .009 \\
\hline Dairy intake $(n=14)$ & $3.1(2.6)$ & $3.8(3.1)$ & $4.1(2.7)$ & .84 \\
\hline Nut intake $(n=20)$ & $6.2(3.3)^{\mathrm{c}}$ & $7.0(2.6)^{\mathrm{c}}$ & $8.4(2.5)^{\mathrm{c}}$ & .009 \\
\hline Intake of sugar-containing beverages $(\mathrm{n}=3$ ) & $1.9(1.8)$ & $5.5(5.0)$ & $6.6(2.8)$ & $-{ }^{\mathrm{d}}$ \\
\hline Total DHDI (sum of all food categories; $n=34$ ) & $52.9(13.1)^{\mathrm{c}}$ & $56.5(11.3)^{\mathrm{c}}$ & $57.2(11.5)^{\mathrm{c}}$ & $<.001$ \\
\hline Carotenoid levels in blood $(\mu \mathrm{mol} / \mathrm{L} ; \mathrm{t}=0, \mathrm{n}=36 ; \mathrm{t}=8, \mathrm{n}=34 ; \mathrm{t}=16, \mathrm{n}=33$ ) & $1.21(0.43)$ & $1.39(0.46)$ & $1.42(0.56)$ & .66 \\
\hline
\end{tabular}

${ }^{a}$ Only participants who included the specific food category in their individual dietary behavior change strategy are included in the analysis.

${ }^{\mathrm{b}}$ DHDI: Dutch Healthy Diet Index.

${ }^{\mathrm{c}}$ No significant difference following the post hoc analysis.

${ }^{\mathrm{d}}$ Not available (as the sample size was not sufficient to obtain reliable statistical output).

\section{Effect of Personalized Advice on Metabolic Health Parameters and Health Score}

After 16 weeks of intervention, triglycerides, HDL cholesterol, LDL cholesterol, BMI, waist circumference, C-peptide, and HOMA-IR were all significantly improved (Table 4). Plasma glucose increased significantly by $0.23 \mathrm{nmol} / \mathrm{L}(P=.04$; Table $4)$. The overall health score significantly improved by 0.27 points on a scale from 1 (MetS reference) to 2 (healthy reference; $P<.001$; Table 4). Improvement in HDL cholesterol had the strongest overall impact on the increase in the health score, indicated by the high correlation between their changes from week 0 to week $16(\rho=0.97 ; P<.001)$, whereas glucose, C-peptide, triglycerides, and LDL cholesterol changes were not significantly correlated with the increase in health score.

No significant correlation was found between the changes in the total DHDI and health scores $(\rho=0.12 ; P=.52$; Figure 2$)$. In particular, 9 subjects who did not improve total DHDI still showed an increased health score after 16 weeks (Figure 2). Significant correlations were found between changes in the total dietary scores and triglycerides $(\rho=0.58 ; P<.001)$. 
Table 4. Metabolic health parameters assessed at $\mathrm{t}=0,8$, and 16 weeks.

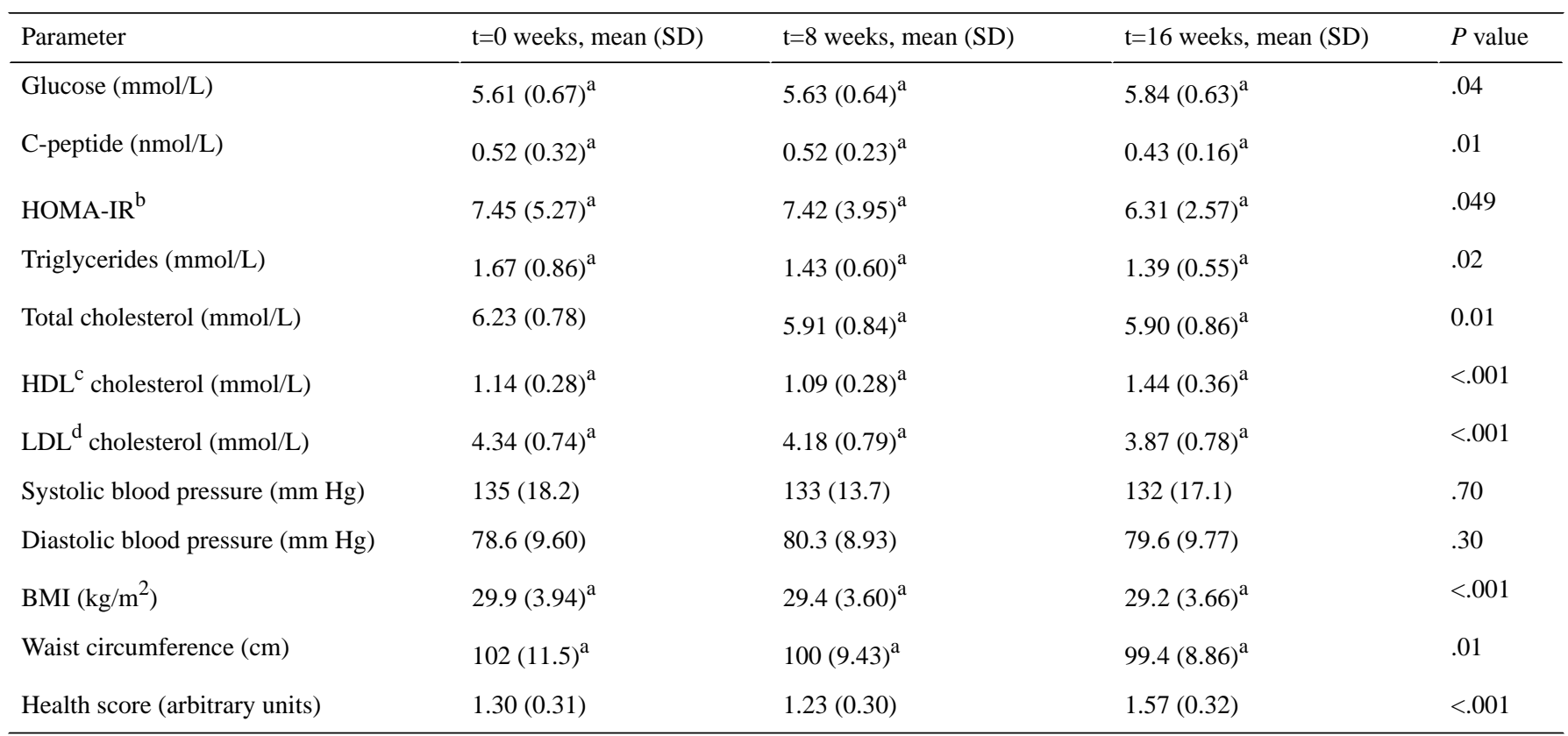

${ }^{\mathrm{a}}$ No significant difference following the post hoc analysis.

${ }^{\mathrm{b}}$ HOMA-IR: homeostatic model assessment-insulin resistance; calculated based on glucose and C-peptide [50].

${ }^{\mathrm{c}} \mathrm{HDL}$ : high-density lipoprotein.

${ }^{\mathrm{d}}$ LDL: low-density lipoprotein. 
Figure 2. Association between the $\Delta$ dietary scores and $\Delta$ health scores calculated between week 0 and week 16 of the study.

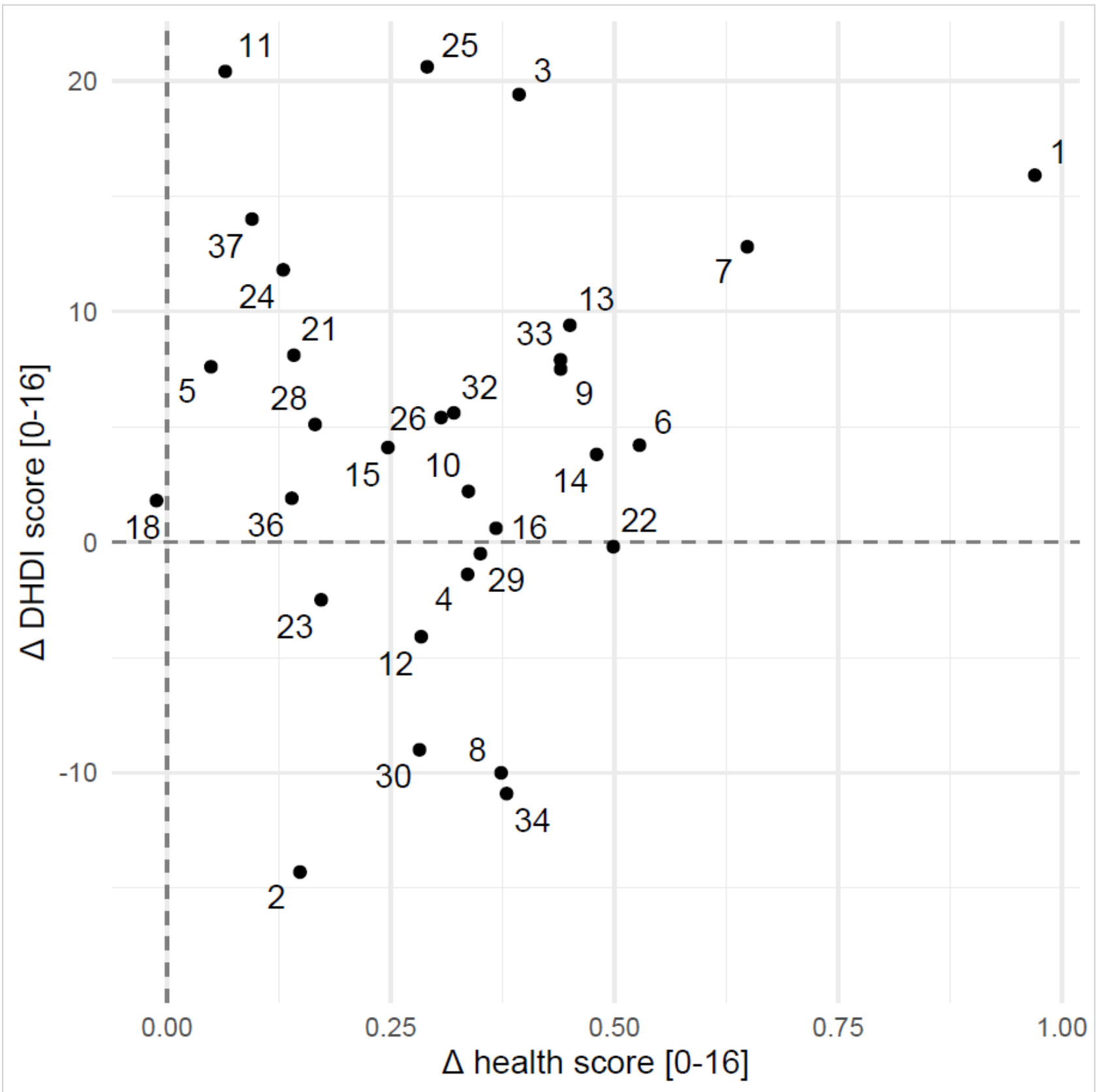

\section{Self-Perceived Health and Consumer Experiences}

The mean scores for self-perceived health, self-perceived healthiness of the diet, and satisfaction with the diet, as reported by the participants at baseline and end, are shown in Table 5. All three scores were significantly improved at the end of the study compared with baseline (self-perceived health: +0.67 , $P=.005$; self-perceived healthiness of the diet: $+1.06, P<.001$; satisfaction with the diet: $+0.94, P=.001)$. In addition, participants reported positive mean scores on how helpful the personalized advice and feedback were to improve their diet. In addition, they were positive about continuing the advice after completion of the study and on advising other people to obtain personalized advice, as in this study. Participants would not be willing to pay for (parts of) this program. 
Table 5. Self-perceived health, self-perceived healthiness of the diet, and satisfaction with the diet as reported at $\mathrm{t}=0$ and 16 weeks.

\begin{tabular}{|c|c|c|c|}
\hline Self-perceived health items & $\mathrm{t}=0$ weeks, mean $(\mathrm{SD})$ & $\mathrm{t}=16$ weeks, mean $(\mathrm{SD})$ & $P$ value \\
\hline Self-perceived health ${ }^{\mathrm{a}}$ & $4.68(1.07)$ & $5.35(1.10)$ & .005 \\
\hline Self-perceived healthiness of $\operatorname{diet}^{\mathrm{a}}$ & $4.50(1.05)$ & $5.56(0.96)$ & $<.001$ \\
\hline Satisfaction with $\operatorname{diet}^{\mathrm{b}}$ & $4.35(1.39)$ & $5.29(1.14)$ & .001 \\
\hline \multicolumn{4}{|l|}{ Consumer experiences $^{c}$} \\
\hline The personalized advice helped me to improve my diet & $-{ }^{\mathrm{d}}$ & $5.7(1.5)$ & - \\
\hline The feedback helped me to improve my diet & - & $5.4(1.4)$ & - \\
\hline If possible I would continue taking part in this program & - & $4.7(2.0)$ & - \\
\hline $\begin{array}{l}\text { I would recommend people in my surroundings to obtain personalized advice like } \\
\text { in this study }\end{array}$ & - & $5.0(1.8)$ & - \\
\hline I would be willing to pay for this program & - & $2.5(1.7)$ & - \\
\hline
\end{tabular}

a 7-point Likert scale, ranging from "very unhealthy" to "very healthy."

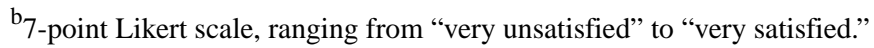

${ }^{\mathrm{c}} 7$-point Likert scale, ranging from "completely disagree" to "completely agree."

${ }^{\mathrm{d}}$ Consumer experiences were only assessed at the end of the study $(\mathrm{t}=16)$.

\section{Discussion}

\section{Principal Findings}

With the aim of exploring the combined behavioral and metabolic health effects in relation to personalized nutrition, we have shown that personalized dietary advice delivered through an automated advice system and discussed by a dietitian with the participant has a significant positive effect on dietary behavior, with a concurring beneficial impact on metabolic health in consumers at risk of MetS. Moreover, the perception of health and healthiness of and satisfaction with the diet improved.

Most earlier studies have shown the impact of personalized dietary advice either on dietary intake or on metabolic health parameters. In this study, we build upon the research described by Doets et al [36] by focusing on the combined analysis of dietary intake, metabolic health, and perceived health. In this previous study, we evaluated the potential of digitally delivered personalized lifestyle advice for improving well-being compared with general dietary advice in a population of active seniors. Well-being was operationalized by self-perceived health and well-being as well as biological measures, including markers of metabolic health and physical function tests. Despite some clear limitations with respect to the target population (eg, already having a healthy diet), the short intervention duration ( 9 weeks), the provided feedback (all participants, including the control group, received individual feedback on their health and well-being), and the intake tools used for monitoring dietary behavior, the results showed that personalized lifestyle advice might have the potential to improve health outcomes as compared with general lifestyle advice.

Compared with Doets et al [36], the study design was improved by prolonging the study duration, including an individual behavior change strategy, selecting an at-risk population, and increasing the frequency of feedback on individual metabolic health.

Interestingly, our results revealed no correlation between the effect on dietary behavior and metabolic health, although both variables showed a significant improvement.

In our study, there was a large variation in the personalized advice between participants, as the advice was tailored to individual metabolic health status as well as dietary quality. Most participants in our study sample incorporated improved intake of vegetables, oils and fats, nuts, and wholegrain products in their behavior change strategy $(n \geq 19)$. Among these, participants seemed to comply with the advice for wholegrain products and nuts, especially as these two food groups significantly improved over time. In contrast, no changes were observed in vegetables, oils, and fats. These results suggest that it is easier for motivated participants to replace refined products with wholegrain products or to include nuts in their dietary patterns as compared with increasing vegetable intake or changing the type of fat for the preparation of meals or for bread spread. Previous systematic reviews have shown significant pooled effects of dietary advice interventions on increased intake of fruits, vegetables, total fiber, and total fat [51-53]. However, most of these reviewed studies focused on changing a single dietary behavior aspect in line with general recommendations rather than optimizing dietary intake in view of improved individual health. A recent study by Rijnaarts et al [54] showed that providing fiber-rich alternatives via an automated, personalized advice system increased adherence to recommendations as compared with generic advice, confirming the effectiveness of a personalized advice system and replacing refined products with wholegrain products.

Although our results indicated an improvement over time for fruit, fish, dairy, and intake of sugar-containing beverages, these effects turned out to be nonsignificant as only a small number 
of individuals included these food groups in their behavior change strategy $(\mathrm{n} \leq 14)$.

Several studies have reviewed available behavior change techniques that are effective for dietary behavior change [55-57]. They demonstrated that tailoring, instructions, goal setting, and feedback are effective intervention elements for evoking dietary behavior change. The personalized intervention we used in the study combined several behavior change techniques to facilitate behavior change: feedback on health (what is the actual health situation), feedback on behavior (which dietary changes are relevant for the individual based on parameters of health and diet), advice on how to change behavior (how these changes can be made in terms of product choice), and individual goal setting (what does the individual want to change, ie, behavior change strategy) [57]. Problem solving and social comparison seem to be other relevant behavior strategies to further improve our intervention. These strategies may be especially relevant for improving compliance with advice on fruit and vegetable intake $[52,55]$.

\section{Effectiveness of Intervention on Metabolic Health}

We hypothesized that by optimizing the quality of the diet in terms of adherence to Dutch dietary guidelines on specific food groups, we were able to improve the metabolic health of our participants. Our analysis indeed showed significant improvements in metabolic health; however, whether these effects were due to improvements in diet quality could not be substantiated. Previous reviews have shown that the restriction of total energy intake, carbohydrate, or fat is a successful strategy to improve metabolic health status. Furthermore, enriching the diet with monounsaturated fatty acids (nuts and olive oil) or omega-3 fatty acids (fish) has been proven effective, especially in improving lipid profiles [7,58,59].

Although the absolute health score is also determined by subtle changes in triglycerides, glucose, C-peptide, and LDL cholesterol, it seems that the relatively strong $\Delta$ HDL cholesterol is the main driver for the change in the health score. It is known from the literature that HDL levels are affected by the increased consumption of fish and unsaturated fatty acids and decreased consumption of saturated fatty acids [60,61]. Interestingly, in our data, the increase in HDL cholesterol could not be significantly related to any specific dietary improvement. Apart from the fact that the statistical power may not have allowed it, this observation may be related to a confounding effect of activity. Results from a meta-analysis showed a highly significant relationship between physical activity and HDL cholesterol levels [62].

\section{Effectiveness of Intervention on Self-Perceived Health}

Self-perceived health summarizes the objective and subjective aspects of health within the perceptual framework of an individual. Some studies suggest that although the criteria for judging health status may vary between individuals, it is a valid indicator of overall health status and use of health services $[63,64]$. However, the cross-sectional association between actual metabolic health and perceived health remains unclear [65]. Previous intervention studies have shown a clear link between improved health behaviors and better self-perceived health scores, supporting our findings $[64,66,67]$. From the perspective of maintaining behavior change, improvement in self-perceived health in the short term is highly relevant as it helps individuals to stay motivated, allowing the behavior change to persist over a longer period.

\section{Lessons Learned}

Participants may have become more aware of their dietary behavior throughout the study, which may have influenced their answers to the DHDI questionnaire, causing a learning bias [68]. Together with the fact that no control period was included, this may have influenced the dietary scores over time. In future studies, it is recommended to include a learning period before the start of the study to minimize the effect of learning.

No control group was included, which is a general challenge in studies investigating the efficacy of personalized nutrition. Therefore, it is not possible to separate the effect of diet from the potential effect of general health improvement as a behavioral consequence of taking part in the study. A semiplacebo control may be reached by comparing personalized advice with generic advice $[54,69]$ or by allowing participants to be their own control by starting with a free-living run-in period without intervention. Furthermore, N-of-1 (or single-subject) study designs focusing on one individual could be a good fit to study research questions related to personalized dietary advice in the future. In N-of-1 designs, the optimal intervention for a specific individual is studied rather than an average individual from a target population.

Although we could confirm the assumption that personalized dietary advice is effective in improving both overall dietary behavior (total DHDI score) and overall metabolic health (health score), interestingly, there was no significant correlation. It should be noted that the pilot study only included 34 individuals, all of whom received personalized dietary advice. In addition, there are some limitations to the DHDI score, in which each food category is weighted equally in the total score. An adjusted total score in which the food categories relevant for MetS would outweigh the other food groups could possibly reveal a significant effect.

In addition to the positive effects of improved dietary quality, previous research has also demonstrated the beneficial effects of moderate- to high-intensity physical activity training on lipid profile, BP, and C-reactive protein [70,71]. In our study, we did not provide any advice on increasing physical activity; however, the study participants were invited to use a health watch, providing general feedback on daily activity levels. Owing to unforeseen practical reasons, these health watches were only available during the second half of the study period. Therefore, we were not able to evaluate possible changes in activity levels during the study. For future studies, it is highly recommended to include physical activity monitoring using either a device or a validated questionnaire.

Contrary to our expectations, these data illustrate that positive effects at the population level are not necessarily indicative of associations between diet and health. We can thus conclude that personalized dietary advice works for dietary behavior and health, but the data did not allow us to conclude that metabolic 
health was improved as a consequence of dietary improvement. A larger sample size with a more equal distribution of men and women and the addition of a control group to the study design are warranted to further investigate and understand the association between diet and health at the individual level. Furthermore, a follow-up after a longer period (eg, 6 months or 1 year) would allow to determine whether initiated behavior changes are maintained over time.

\section{Conclusions}

In this exploratory pilot study in individuals at risk for MetS and motivated to change behavior, personalized dietary advice was indicative of positive effects on self-perceived health, dietary behavior, and metabolic health. The lack of association between diet and health improvement is reflective of the individual nature of diet-health relations and underlines the need for an integrated analysis focusing on individual improvements. The study was performed in a do-it-yourself setting, highlighting the potential of evidence-based at-home improvement of health through dietary changes. Follow-up studies are needed to confirm these effects and evaluate the maintenance of dietary behavioral changes.

\section{Acknowledgments}

The authors gratefully acknowledge all participants in the study. Furthermore, they thank Meeke Ummels for her contribution to the study execution and Quinten Ducarmon and Angelique Speulman-Saat for their support in data collection.

This research was supported by the Dutch Personalized Nutrition and Health program funded by the Dutch Top Sector Agri \& Food (TKI-AF-15262). The funder had no role in the study design, data collection and analysis, decision to publish, or preparation of the manuscript.

\section{Authors' Contributions}

ELD, FPMH, MT, and AB designed the study; MT, AB, and TVDB designed the automated advice system; SVDH coordinated the study execution; TVDB, WJVDB, and SVDH analyzed the data; SVDH, FPMH, ELD, and WJVDB prepared the manuscript; $\mathrm{MT}, \mathrm{AB}$, and TVDB reviewed the manuscript.

\section{Conflicts of Interest}

None declared.

\section{Multimedia Appendix 1}

An overview of the telephone consultation in stage 2 of the personalized advice with the trained dietitian (example of one food group for one participant) and standardized coefficients of the features in the health space model.

[DOCX File, 16 KB-Multimedia Appendix 1]

\section{References}

1. Alberti KG, Zimmet P, Shaw J, IDF Epidemiology Task Force Consensus Group. The metabolic syndrome--a new worldwide definition. Lancet 2005;366(9491):1059-1062. [doi: 10.1016/S0140-6736(05)67402-8] [Medline: 16182882]

2. Kaur J. A comprehensive review on metabolic syndrome. Cardiol Res Pract 2014;2014:943162 [FREE Full text] [doi: 10.1155/2014/943162] [Medline: 24711954]

3. Kolovou GD, Anagnostopoulou KK, Salpea KD, Mikhailidis DP. The prevalence of metabolic syndrome in various populations. Am J Med Sci 2007 Jun;333(6):362-371. [doi: 10.1097/MAJ.0b013e318065c3a1] [Medline: 17570989]

4. Park Y, Zhu S, Palaniappan L, Heshka S, Carnethon MR, Heymsfield SB. The metabolic syndrome: prevalence and associated risk factor findings in the US population from the Third National Health and Nutrition Examination Survey, 1988-1994. Arch Intern Med 2003 Feb 24;163(4):427-436 [FREE Full text] [doi: 10.1001/archinte.163.4.427] [Medline: 12588201]

5. Alberti KG, Eckel RH, Grundy SM, Zimmet PZ, Cleeman JI, Donato KA, et al. Harmonizing the metabolic syndrome: a joint interim statement of the International Diabetes Federation Task Force on Epidemiology and Prevention; National Heart, Lung, and Blood Institute; American Heart Association; World Heart Federation; International Atherosclerosis Society; and International Association for the Study of Obesity. Circulation 2009 Oct 20;120(16):1640-1645 [FREE Full text] [doi: 10.1161/CIRCULATIONAHA.109.192644] [Medline: 19805654]

6. Martínez-González MA, Martín-Calvo N. The major European dietary patterns and metabolic syndrome. Rev Endocr Metab Disord 2013 Sep;14(3):265-271. [doi: 10.1007/s11154-013-9264-6] [Medline: 23979531]

7. Andersen CJ, Fernandez ML. Dietary strategies to reduce metabolic syndrome. Rev Endocr Metab Disord 2013 Sep;14(3):241-254. [doi: 10.1007/s11154-013-9251-y] [Medline: 23943309]

8. Kastorini C, Milionis HJ, Esposito K, Giugliano D, Goudevenos JA, Panagiotakos DB. The effect of Mediterranean diet on metabolic syndrome and its components: a meta-analysis of 50 studies and 534,906 individuals. J Am Coll Cardiol 2011 Mar 15;57(11):1299-1313 [FREE Full text] [doi: 10.1016/j.jacc.2010.09.073] [Medline: 21392646] 
9. Minehira K, Tappy L. Dietary and lifestyle interventions in the management of the metabolic syndrome: present status and future perspective. Eur J Clin Nutr 2002 Dec;56(12):7 p following 1262. [doi: 10.1038/sj.ejcn.1601645] [Medline: 12494312]

10. Azadbakht L, Mirmiran P, Esmaillzadeh A, Azizi T, Azizi F. Beneficial effects of a dietary approaches to stop hypertension eating plan on features of the metabolic syndrome. Diabetes Care 2005 Dec;28(12):2823-2831. [doi: 10.2337/diacare.28.12.2823] [Medline: 16306540]

11. Bender N, Portmann M, Heg Z, Hofmann K, Zwahlen M, Egger M. Fish or n3-PUFA intake and body composition: a systematic review and meta-analysis. Obes Rev 2014 Aug;15(8):657-665. [doi: 10.1111/obr.12189] [Medline: 24891155]

12. Engel S, Tholstrup T. Butter increased total and LDL cholesterol compared with olive oil but resulted in higher HDL cholesterol compared with a habitual diet. Am J Clin Nutr 2015 Aug;102(2):309-315. [doi: 10.3945/ajcn.115.112227] [Medline: 26135349]

13. Giacco R, Costabile G, Della Pepa G, Anniballi G, Griffo E, Mangione A, et al. A whole-grain cereal-based diet lowers postprandial plasma insulin and triglyceride levels in individuals with metabolic syndrome. Nutr Metab Cardiovasc Dis 2014 Aug;24(8):837-844. [doi: 10.1016/j.numecd.2014.01.007] [Medline: 24598599]

14. Harris Jackson K, West SG, Vanden Heuvel JP, Jonnalagadda SS, Ross AB, Hill AM, et al. Effects of whole and refined grains in a weight-loss diet on markers of metabolic syndrome in individuals with increased waist circumference: a randomized controlled-feeding trial. Am J Clin Nutr 2014 Aug;100(2):577-586 [FREE Full text] [doi:

10.3945/ajen.113.078048] [Medline: 24944054]

15. Hu FB. Resolved: there is sufficient scientific evidence that decreasing sugar-sweetened beverage consumption will reduce the prevalence of obesity and obesity-related diseases. Obes Rev 2013 Aug;14(8):606-619 [FREE Full text] [doi: 10.1111/obr.12040] [Medline: 23763695]

16. Poulsen SK, Due A, Jordy AB, Kiens B, Stark KD, Stender S, et al. Health effect of the New Nordic Diet in adults with increased waist circumference: a 6-mo randomized controlled trial. Am J Clin Nutr 2014 Jan;99(1):35-45. [doi: 10.3945/ajen.113.069393] [Medline: 24257725]

17. Romaguera D, Ängquist L, Du H, Jakobsen MU, Forouhi NG, Halkjær J, et al. Food composition of the diet in relation to changes in waist circumference adjusted for body mass index. PLoS One 2011;6(8):e23384 [FREE Full text] [doi: 10.1371/journal.pone.0023384] [Medline: 21858094]

18. Sayon-Orea C, Martínez-González MA, Ruiz-Canela M, Bes-Rastrollo M. Associations between yogurt consumption and weight gain and risk of obesity and metabolic syndrome: a systematic review. Adv Nutr 2017 Jan;8(1):146S-154S. [doi: 10.3945/an.115.011536] [Medline: 28096138]

19. Schwingshackl L, Hoffmann G, Kalle-Uhlmann T, Arregui M, Buijsse B, Boeing H. Fruit and vegetable consumption and changes in anthropometric variables in adult populations: a systematic review and meta-analysis of prospective cohort studies. PLoS One 2015;10(10):e0140846 [FREE Full text] [doi: 10.1371/journal.pone.0140846] [Medline: 26474158]

20. Schwingshackl L, Hoffmann G, Schwedhelm C, Kalle-Uhlmann T, Missbach B, Knüppel S, et al. Consumption of dairy products in relation to changes in anthropometric variables in adult populations: a systematic review and meta-analysis of cohort studies. PLoS One 2016;11(6):e0157461 [FREE Full text] [doi: 10.1371/journal.pone.0157461] [Medline: 27310919]

21. Zaribaf F, Falahi E, Barak F, Heidari M, Keshteli AH, Yazdannik A, et al. Fish consumption is inversely associated with the metabolic syndrome. Eur J Clin Nutr 2014 Apr;68(4):474-480. [doi: 10.1038/ejcn.2014.5] [Medline: 24549028]

22. Adams SH, Anthony JC, Carvajal R, Chae L, Khoo CS, Latulippe ME, et al. Perspective: guiding principles for the implementation of personalized nutrition approaches that benefit health and function. Adv Nutr 2020 Jan 1;11(1):25-34 [FREE Full text] [doi: 10.1093/advances/nmz086] [Medline: 31504115]

23. Brug J, Campbell M, van Assema P. The application and impact of computer-generated personalized nutrition education: a review of the literature. Patient Educ Couns 1999 Feb;36(2):145-156. [doi: 10.1016/s0738-3991(98)00131-1] [Medline: 10223019]

24. Bull FC, Kreuter MW, Scharff DP. Effects of tailored, personalized and general health messages on physical activity. Patient Educ Couns 1999 Feb;36(2):181-192. [doi: 10.1016/s0738-3991(98)00134-7] [Medline: 10223022]

25. Celis-Morales C, Livingstone KM, Marsaux CF, Forster H, O'Donovan CB, Woolhead C, et al. Design and baseline characteristics of the Food4Me study: a web-based randomised controlled trial of personalised nutrition in seven European countries. Genes Nutr 2015 Jan;10(1):450 [FREE Full text] [doi: 10.1007/s12263-014-0450-2] [Medline: 25491748]

26. Fjeldsoe BS, Marshall AL, Miller YD. Behavior change interventions delivered by mobile telephone short-message service. Am J Prev Med 2009 Feb;36(2):165-173. [doi: 10.1016/j.amepre.2008.09.040] [Medline: 19135907]

27. Krebs P, Prochaska JO, Rossi JS. A meta-analysis of computer-tailored interventions for health behavior change. Prev Med 2010;51(3-4):214-221 [FREE Full text] [doi: 10.1016/j.ypmed.2010.06.004] [Medline: 20558196]

28. Kris-Etherton PM, Taylor DS, Smiciklas-Wright H, Mitchell DC, Bekhuis TC, Olson BH, et al. High-soluble-fiber foods in conjunction with a telephone-based, personalized behavior change support service result in favorable changes in lipids and lifestyles after 7 weeks. J Am Diet Assoc 2002 Apr;102(4):503-510. [doi: 10.1016/s0002-8223(02)90116-1] [Medline: $\underline{11985406]}$

29. Marcus BH, Napolitano MA, King AC, Lewis BA, Whiteley JA, Albrecht A, et al. Telephone versus print delivery of an individualized motivationally tailored physical activity intervention: Project STRIDE. Health Psychol 2007 Jul;26(4):401-409. [doi: 10.1037/0278-6133.26.4.401] [Medline: 17605559] 
30. Parekh S, Vandelanotte C, King D, Boyle FM. Improving diet, physical activity and other lifestyle behaviours using computer-tailored advice in general practice: a randomised controlled trial. Int J Behav Nutr Phys Act 2012 Sep 11;9:108 [FREE Full text] [doi: 10.1186/1479-5868-9-108] [Medline: 22963354]

31. Bouwman J, Vogels JT, Wopereis S, Rubingh CM, Bijlsma S, Ommen BV. Visualization and identification of health space, based on personalized molecular phenotype and treatment response to relevant underlying biological processes. BMC Med Genomics 2012 Jan 6;5:1 [FREE Full text] [doi: 10.1186/1755-8794-5-1] [Medline: 22221319]

32. van Ommen B, van den Broek T, de Hoogh I, van Erk M, van Someren E, Rouhani-Rankouhi T, et al. Systems biology of personalized nutrition. Nutr Rev 2017 Aug 1;75(8):579-599 [FREE Full text] [doi: 10.1093/nutrit/nux029] [Medline: 28969366]

33. Celis-Morales C, Lara J, Mathers JC. Personalising nutritional guidance for more effective behaviour change. Proc Nutr Soc 2015 May;74(2):130-138. [doi: 10.1017/S0029665114001633] [Medline: 25497396]

34. Michie S, Ashford S, Sniehotta FF, Dombrowski SU, Bishop A, French DP. A refined taxonomy of behaviour change techniques to help people change their physical activity and healthy eating behaviours: the CALO-RE taxonomy. Psychol Health 2011 Nov;26(11):1479-1498. [doi: 10.1080/08870446.2010.540664] [Medline: 21678185]

35. Forster H, Walsh MC, O'Donovan CB, Woolhead C, McGirr C, Daly EJ, et al. A dietary feedback system for the delivery of consistent personalized dietary advice in the web-based multicenter food4me study. J Med Internet Res 2016 Jun 30;18(6):e150 [FREE Full text] [doi: 10.2196/jmir.5620] [Medline: 27363307]

36. Doets EL, de Hoogh IM, Holthuysen N, Wopereis S, Verain MC, van den Puttelaar J, et al. Beneficial effect of personalized lifestyle advice compared to generic advice on wellbeing among Dutch seniors - An explorative study. Physiol Behav 2019 Oct 15;210:112642 [FREE Full text] [doi: 10.1016/j.physbeh.2019.112642] [Medline: 31394106]

37. Poínhos R, van der Lans IA, Rankin A, Fischer AR, Bunting B, Kuznesof S, et al. Psychological determinants of consumer acceptance of personalised nutrition in 9 European countries. PLoS One 2014;9(10):e110614 [FREE Full text] [doi: 10.1371/journal.pone.0110614] [Medline: 25334009]

38. Héroux M, Watt M, McGuire KA, Berardi JM. A personalized, multi-platform nutrition, exercise, and lifestyle coaching program: a pilot in women. Internet Interv 2017 Mar;7:16-22 [FREE Full text] [doi: 10.1016/j.invent.2016.12.002] [Medline: $\underline{30135822]}$

39. Fjeldsoe B, Neuhaus M, Winkler E, Eakin E. Systematic review of maintenance of behavior change following physical activity and dietary interventions. Health Psychol 2011 Jan;30(1):99-109. [doi: 10.1037/a0021974] [Medline: 21299298]

40. Prochaska JJ, Prochaska JO. A review of multiple health behavior change interventions for primary prevention. Am J Lifestyle Med 2011 May;5(3):- [FREE Full text] [doi: 10.1177/1559827610391883] [Medline: 24358034]

41. Looman M, Feskens EJ, de Rijk M, Meijboom S, Biesbroek S, Temme EH, et al. Development and evaluation of the dutch healthy diet index 2015. Public Health Nutr 2017 Sep;20(13):2289-2299. [doi: 10.1017/S136898001700091X] [Medline: 28625202]

42. Sakhi AK, Bastani NE, Ellingjord-Dale M, Gundersen TE, Blomhoff R, Ursin G. Feasibility of self-sampled dried blood spot and saliva samples sent by mail in a population-based study. BMC Cancer 2015 Apr 11;15:265 [FREE Full text] [doi: 10.1186/s12885-015-1275-0] [Medline: 25886002]

43. Brink L, Postema-Smeets A, Stafleu A, Wolvers D. RichtlijnenSchijf van Vijf. Voedingscentrum. 2016. URL: https://www. voedingscentrum.nl/Assets/Uploads/voedingscentrum/Documents/Professionals/Schijf\%20van\%20Vijf/

Richtlijnen\%20Schijf\%20van\%20Vijf.pdf [accessed 2021-06-11]

44. Richtlijnen Goede Voeding. Den Haag: Health Council of the Netherlands; 2015.

45. van den Broek TJ, Bakker GC, Rubingh CM, Bijlsma S, Stroeve JH, van Ommen B, et al. Ranges of phenotypic flexibility in healthy subjects. Genes Nutr 2017;12:32 [FREE Full text] [doi: 10.1186/s12263-017-0589-8] [Medline: 29225708]

46. National Health and Nutrition Examination Survey Data. Centers for Disease Control and Prevention. 2003. URL: https:/ /wwwn.cdc.gov/nchs/nhanes/ContinuousNhanes/overview.aspx?BeginYear=2003 [accessed 2019-05-11]

47. Alberti KGM, Zimmet P, Shaw J. Metabolic syndrome--a new world-wide definition. A consensus statement from the international diabetes federation. Diabet Med 2006 May;23(5):469-480. [doi: 10.1111/j.1464-5491.2006.01858.x] [Medline: $\underline{16681555]}$

48. Kolde R, Laur S, Adler P, Vilo J. Robust rank aggregation for gene list integration and meta-analysis. Bioinformatics 2012 Feb 15;28(4):573-580 [FREE Full text] [doi: 10.1093/bioinformatics/btr709] [Medline: 22247279]

49. Benjamini Y, Hochberg Y. Controlling the false discovery rate: a practical and powerful approach to multiple testing. J R Stat Soc Series B Stat Methodol 2018 Dec 5;57(1):289-300. [doi: 10.1111/j.2517-6161.1995.tb02031.x]

50. Matthews DR, Hosker JP, Rudenski AS, Naylor BA, Treacher DF, Turner RC. Homeostasis model assessment: insulin resistance and beta-cell function from fasting plasma glucose and insulin concentrations in man. Diabetologia 1985 Jul;28(7):412-419. [doi: 10.1007/BF00280883] [Medline: 3899825]

51. Rees K, Dyakova M, Wilson N, Ward K, Thorogood M, Brunner E. Dietary advice for reducing cardiovascular risk. Cochrane Database Syst Rev 2013 Dec 06(12):CD002128. [doi: 10.1002/14651858.CD002128.pub5] [Medline: 24318424]

52. Thomson CA, Ravia J. A systematic review of behavioral interventions to promote intake of fruit and vegetables. J Am Diet Assoc 2011 Oct;111(10):1523-1535. [doi: 10.1016/j.jada.2011.07.013] [Medline: 21963019] 
53. Whatnall MC, Patterson AJ, Ashton LM, Hutchesson MJ. Effectiveness of brief nutrition interventions on dietary behaviours in adults: a systematic review. Appetite 2018 Jan 1;120:335-347. [doi: 10.1016/j.appet.2017.09.017] [Medline: 28947184]

54. Rijnaarts I, de Roos NM, Wang T, Zoetendal EG, Top J, Timmer M, et al. Increasing dietary fibre intake in healthy adults using personalised dietary advice compared with general advice: a single-blind randomised controlled trial. Public Health Nutr 2021 Apr;24(5):1117-1128 [ [FREE Full text] [doi: 10.1017/S1368980020002980] [Medline: 32943128]

55. Ammerman AS, Lindquist CH, Lohr KN, Hersey J. The efficacy of behavioral interventions to modify dietary fat and fruit and vegetable intake: a review of the evidence. Prev Med 2002 Jul;35(1):25-41. [doi: 10.1006/pmed.2002.1028] [Medline: $\underline{12079438}]$

56. Macready AL, Fallaize R, Butler LT, Ellis JA, Kuznesof S, Frewer LJ, et al. Application of behavior change techniques in a personalized nutrition electronic health intervention study: protocol for the web-based food4me randomized controlled trial. JMIR Res Protoc 2018 Apr 9;7(4):e87 [FREE Full text] [doi: 10.2196/resprot.8703] [Medline: 29631993]

57. Michie S, Richardson M, Johnston M, Abraham C, Francis J, Hardeman W, et al. The behavior change technique taxonomy (v1) of 93 hierarchically clustered techniques: building an international consensus for the reporting of behavior change interventions. Ann Behav Med 2013 Aug;46(1):81-95. [doi: 10.1007/s12160-013-9486-6] [Medline: 23512568]

58. Abete I, Goyenechea E, Zulet MA, Martínez JA. Obesity and metabolic syndrome: potential benefit from specific nutritional components. Nutr Metab Cardiovasc Dis 2011 Sep;21(Suppl 2):B1-15. [doi: 10.1016/j.numecd.2011.05.001] [Medline: 21764273]

59. de la Iglesia R, Loria-Kohen V, Zulet MA, Martinez JA, Reglero G, Ramirez de Molina A. Dietary strategies implicated in the prevention and treatment of metabolic syndrome. Int J Mol Sci 2016 Nov 10;17(11):- [FREE Full text] [doi: 10.3390/ijms17111877] [Medline: 27834920]

60. Balk EM, Lichtenstein AH, Chung M, Kupelnick B, Chew P, Lau J. Effects of omega-3 fatty acids on serum markers of cardiovascular disease risk: a systematic review. Atherosclerosis 2006 Nov;189(1):19-30. [doi:

10.1016/j.atherosclerosis.2006.02.012] [Medline: 16530201]

61. Mensink RP, Zock PL, Kester AD, Katan MB. Effects of dietary fatty acids and carbohydrates on the ratio of serum total to HDL cholesterol and on serum lipids and apolipoproteins: a meta-analysis of 60 controlled trials. Am J Clin Nutr 2003 May;77(5):1146-1155. [doi: 10.1093/ajcn/77.5.1146] [Medline: 12716665]

62. Kodama S, Tanaka S, Saito K, Shu M, Sone Y, Onitake F, et al. Effect of aerobic exercise training on serum levels of high-density lipoprotein cholesterol: a meta-analysis. Arch Intern Med 2007 May 28;167(10):999-1008. [doi: 10.1001/archinte.167.10.999] [Medline: 17533202]

63. Machón M, Vergara I, Dorronsoro M, Vrotsou K, Larrañaga I. Self-perceived health in functionally independent older people: associated factors. BMC Geriatr 2016 Mar 9;16:66 [FREE Full text] [doi: 10.1186/s12877-016-0239-9] [Medline: 26961707]

64. Mood C. Life-style and self-rated global health in Sweden: a prospective analysis spanning three decades. Prev Med 2013 Dec;57(6):802-806 [FREE Full text] [doi: 10.1016/j.ypmed.2013.09.002] [Medline: 24041976]

65. Näslindh-Ylispangar A, Sihvonen M, Vanhanen H, Kekki P. Self-rated health and risk factors for metabolic syndrome among middle-aged men. Public Health Nurs 2005;22(6):515-522. [doi: 10.1111/j.0737-1209.2005.220607.x] [Medline: 16371072]

66. Lara J, McCrum L, Mathers JC. Association of Mediterranean diet and other health behaviours with barriers to healthy eating and perceived health among British adults of retirement age. Maturitas 2014 Nov;79(3):292-298 [FREE Full text] [doi: 10.1016/j.maturitas.2014.07.003] [Medline: 25096829]

67. Piko BF. Self-perceived health among adolescents: the role of gender and psychosocial factors. Eur J Pediatr 2007 Jul;166(7):701-708. [doi: 10.1007/s00431-006-0311-0] [Medline: 17120041]

68. Benítez I, Adams BG, He J. An integrated approach to bias in a longitudinal survey in the United Kingdom: assessing construct, method, and item bias in the general health questionnaire (ghq-12). Assessment 2019 Oct;26(7):1194-1206. [doi: 10.1177/1073191117739979] [Medline: 29117704]

69. Sialvera TE, Papadopoulou A, Efstathiou SP, Trautwein EA, Ras RT, Kollia N, et al. Structured advice provided by a dietitian increases adherence of consumers to diet and lifestyle changes and lowers blood low - density lipoprotein (ldl) - cholesterol: The increasing adherence of consumers to diet \& lifestyle changes to lower (ldl) cholesterol (act) randomised controlled trial. J Hum Nutr Diet 2018 Apr;31(2):197-208. [doi: 10.1111/jhn.12508] [Medline: 28891084]

70. Martins RA, Veríssimo MT, Coelho e Silva MJ, Cumming SP, Teixeira AM. Effects of aerobic and strength-based training on metabolic health indicators in older adults. Lipids Health Dis 2010 Jul 22;9:76 [FREE Full text] [doi: 10.1186/1476-511X-9-76] [Medline: 20663148]

71. Kelley GA, Kelley KS. Aerobic exercise and lipids and lipoproteins in men: a meta-analysis of randomized controlled trials. J Mens Health Gend 2006;3(1):61-70 [ㅌREE Full text] [doi: 10.1016/j.jmhg.2005.09.003] [Medline: 18645633]

\section{Abbreviations \\ BP: blood pressure \\ DBS: dried blood spot}


DHDI: Dutch Healthy Diet Index

HDL: high-density lipoprotein

LDL: low-density lipoprotein

MetS: metabolic syndrome

Edited by $G$ Eysenbach; submitted 15.10.20; peer-reviewed by C Koebnick, B Greggianin; comments to author 25.01.21; revised version received 11.04.21; accepted 19.05.21; published 24.06.21

Please cite as:

van der Haar S, Hoevenaars FPM, van den Brink WJ, van den Broek T, Timmer M, Boorsma A, Doets EL

Exploring the Potential of Personalized Dietary Advice for Health Improvement in Motivated Individuals With Premetabolic Syndrome:

Pretest-Posttest Study

JMIR Form Res 2021;5(6):e25043

URL: https://formative.jmir.org/2021/6/e25043/

doi: $10.2196 / 25043$

PMID:

CSandra van der Haar, Femke P M Hoevenaars, Willem J van den Brink, Tim van den Broek, Mariëlle Timmer, André Boorsma, Esmée L Doets. Originally published in JMIR Formative Research (https://formative.jmir.org), 24.06.2021. This is an open-access article distributed under the terms of the Creative Commons Attribution License (https://creativecommons.org/licenses/by/4.0/), which permits unrestricted use, distribution, and reproduction in any medium, provided the original work, first published in JMIR Formative Research, is properly cited. The complete bibliographic information, a link to the original publication on https://formative.jmir.org, as well as this copyright and license information must be included. 